\title{
Counseling in Primary Care Improves Depression and Quality of Life
}

\author{
Carta M.G ${ }^{4}$, Petretto D ${ }^{1, *}$, Adamo $\mathrm{S}^{4}$, Bhat K. M, ${ }^{2}$ Lecca M.E ${ }^{4}$, Mura G., Carta ${ }^{4}$, Angermeyer $\mathrm{M}^{4,3}$ \\ and Moro M.F \\ ${ }^{I}$ Department of Education, Psychology, Philosopy University of Cagliari, Italy \\ ${ }^{2}$ Department of Neuroscience and Cell Biology, University of Texas Medical Branch School of Medicine, Galveston, \\ Texas, USA \\ ${ }^{3}$ Center for Public Mental Health, Gosing and Wagram, Vienna, Austria \\ ${ }^{4}$ Centro di Psichiatria di Consultazione e Psicosomatica, University of Cagliari and AOU Cagliari, Italy
}

\begin{abstract}
Summary: Introduction: To measure the effectiveness on Quality of Life of adjunctive cognitive behavioral counseling in the setting of General Practitioners (GPs) along with the treatment as usual (TAU;) for the treatment of depression.

Methods: Six month-controlled trial of patients who were referred to randomly assigned GPs (four for experimental group of patients and ten for the control) was done. Experimental sample had 34 patients with DSM-IV diagnosis of Depression (Depressed Episode, Dysthymia, or Adjustment Disorder with Depressed Mood) receiving the TAU supplemented with counseling. Control group had 30 patients with diagnosis of Depression receiving only the TAU.

Results: The Beck Depression Inventory (BDI) score improved in both groups. Patients in the experimental group showed greater improvement compared to the control group at T2. The World Health Organization Quality OF Life Questionnaire (WHOQOL) score also improved in the experimental group but not in the control group. The improvement in the experimental group was statistically significant in terms of both BDI and WHOQOL scores.

Conclusions: Adding counseling to TAU in general medical practice settings is more effective in controlling the symptoms of depression and improving the quality of life as measured over a period of six months, than TAU alone. These results while encouraging, also calls for a larger study involving a largersample size and a longer period of time.
\end{abstract}

Keywords: Counseling, Primary Care, Depression, Quality of Life, Cognitive Behavior Therapy.

\section{INTRODUCTION}

Depressive disorders are considered a serious public health problem, causing high levels of disability, impairment in quality of life, and decreased life expectancy [1]. Moreover, depression is associated with enhanced healthcare visits, work absenteeism, decreased performances at work with elevated direct and indirect health costs $[2,3]$. Epidemiological studies indicate that Depressive Disorders have a high prevalence in primary care, ranging from $2.6 \%$ to as high as $29.5 \%$ [4-6]. Therefore, the role of general practice is central to organizing care and research for mood disorders. In recent decades, a system of co-operation between general practice and secondary medical services has been established [7-10].

This study was carried out in Sardinia (Italy). Fifty percent of the Sardinian population live in communities with less than 5,000 residents, often isolated without access to the secondary care services and include higher proportions of adolescents and elderly due to migration of adult people to urban areas [11]. Such as condition is common in many European countries, particularly in the southern and the east

*Address correspondence to this author at the Centro di Psichiatria di Consultazione e Psicosomatica Via Ospedale 11709100 Cagliari, Italy; Tel/Fax+39070 6093498; E-mail : drpetretto@unica.it ern parts [12]. According to the literature, adolescents and the elderly, the age groups most at risk for suicide, are also the ages who are most unwilling to seek help from public mental health servicefacilities [13], but they are more likely to visit primary care providers. Thus improving care provided by GPs by adding a psychosocial component may offer significant benefits. This can be particularly significant in view of lack of specialized services such as psychiatric consultations in such of area.

This Research aims to evaluate the effectiveness of an integrated intervention option (cognitive behavioral counseling + TAU) on depressive patients administered by GPs in primary care setting. Current literature unequivocally supports the claim that cognitive behavioral psychotherapy simultaneously given with pharmacological treatment, is most effective over a long period of time, and helps prevent relapse [14], diminishes residual symptomatology and reduces the risk of chronicity [15].

The aim of this study is to evaluate the efficacy and feasibility of an adjunctive counseling approach in Primary Care setting for patients who have no ready access to secondary care or specialized psychotherapy.

The subjective perception of quality of life is a construct that is very relevant to measures of outcomes in chronic dis- 
ease [16-18], particularly in patients with diseases that impact heavily the daily life of the affected patients and their families such as depressive disorders [19].

Thus, objective of this study was to evaluate the impairment on quality of life of an adjunctive counseling approach in Primary Care setting for patients who have no ready access to secondary care or specialized psychotherapy.

\section{METHODS}

\section{Catchment Area}

The catchment area has a total population of 20,000 residents, living in six villages (from 1,000 to 6,000 residents). The territory is located in the south westpart of Sardinia, with an average distance of $25 \mathrm{Km}$ of mountain roads from the closest hospital and urban center.

\section{Study Design}

The study is a controlled trial with patients attending to GPs. Fourteen GPs were recruited from the catchment area on the basis of their willingness to participate in the study. The assignment was randomized with four GPs for recruiting the experimental sample, ten for recruiting the control group.The four GPs of the experimental group were working in two villages with 1500 and 3500 residents, respectively. The other ten GPS were in the villages of the same area. The 14participating GPs were given preliminary training in Psychiatric Diagnosis of 10-hours by the PSat the beginning of the trial. The GPs were not reimbursed for their participation.

\section{Sample}

The Inclusion criteria were: Aged 16 years or over;Depressed (Depressed Episode, Adjustment Disorder with depressed Mood, Dysthymic Disorder according DSMIV TR)by a score of $\geq 14$ on Beck depression inventory. The Exclusion criteria were: Severe Depressive symptomatology such as with severe suicidal intent, psychotic symptoms, previously recorded severe manic episodes and need for psychiatric care, restricted mobility and organic brain syndromes.

The experimental group included 42 patients, 28 females and 14 males aged between 16 and 68 years, with a DSM-IV diagnosis of depression (Depressed Episode, Dysthymia, or Adjustment Disorder with Depressed Mood), referred to the counselors by the four GPs over a period of six months.

The control group included patients selected by the other group of ten GP's during the same time period. Controls were matched for severity of depression, measured by total BDI score (score \pm 4 ); age ( \pm 3 years) and sex. For the control group, from among the 69 patients referred to by the GPs, 42 were selected for their match with the experimental group of patients.

Participation in the study was voluntary and written informed consent was obtained from each of the patients. Patients were also informed that they could withdraw their consent to participate at any time, with no negative consequences on their future medical treatment. Patients who wished to withdraw from the study received TAU. Eligible patients were giventhe explanation of the study procedures and were asked to sign an informed consent. The study protocol was approved by the Ethics Committee of the Università Europea del Mediterraneo.

\section{Intervention}

The control group received treatment as usual (TAU) provided by GPs, while the experimental group received TAU by GPs plus cognitive behavior counseling. The counseling was carried out for a period of sixmonths by two trained psychologists in individual sessions once in every two weeks in primary care setting. The training of psychologists consists of a five-days course conducted using case vignettes.

In this study, we used the counseling method described in the manual "Depression: What is it and how to surpass it" [20]. This manual was based on the treatment program developed at the Clinical Research Unit for Anxiety and Depression in Sydney, Australia. [21], focusing on patients who suffer from depression. Because, this manual is written in a simple and clear manner, with specialized terms described in common language to the extent possible. The intervention strategy was based on "active listening and show of empathy towards the patient". This approach is guided by the idea that patients, because of their mental status, are unable to fully recognize their own abilities, and when enlightened, will overcome this mental status. The counselor's job is essentially to facilitate and support the patient during the process, while stimulating the patient to actively participate in the therapy [20]. The manual teaches how to recognize "dysfunctional" thoughts and mistakes in reasoning that are often the basis for depression. It aims to help people to be more balanced and to maintain or regain social relations and proposes a self-help tool for those who suffer from only marginal mental disturbance. In short, a cognitive-behavioral self-healing process is stimulated, an approach characterized by active listening and sympathy typical of traditional counseling, facilitated by a specific manual.

Finally, monthly discussions were conducted between each counselor, theGP and the Psychiatrist (PS) during the course of the study.

\section{Assessment}

The psychiatric diagnoses were given according to DSMIV-TR (APA 2000) [22] by the PS with an external supervision who had not interviewed the patient. In the experimental group, the decision of whether or not a patient receives counseling treatment was madeby the GPs on the basis of their diagnosis and the inclusion criteria.

The evaluation during the trial was carried out in blind (experimental versus control)by four psychologists and two psychiatry residents,

The evaluation criteria used were the Beck Depression Inventory (BDI) [23], the Quality of the Life Questionnaire of the World Health Organization (WHOQOL-Bref) [24,25] and the Clinical Global Impression(CGI, [26]). The evaluations were conducted at the start of the trial, after three months and at the end of the trial ( 6 months). The dosage of daily anti-depressants administered from the beginning to the end of the trial were quantified by defining the minimum daily dose indicated for depression for each antidepressant 
Table 1. Sample Analysis of Patients Completing the Trial

\begin{tabular}{|c|c|c|c|}
\hline & Experimental Cases N=34 & Controls N=30 & Differences by Groups \\
\hline \hline Females & $22(64.7 \%)$ & $20(66.6 \%)$ & $\mathrm{X} 2=0.1, \mathrm{P}=0.9251 \mathrm{DF}$ \\
\hline Age & $42.2 \pm 19.1$ & $42.8 \pm 18.5$ & $\mathrm{~F}=0.1, \mathrm{P}=0.922, \mathrm{DF} 1,62.63$ \\
\hline Antidepressantsat the start & $22(64.7 \%)$ & $23(76.7 \%)$ & $\mathrm{X} 2=0.1, \mathrm{P}=0.9211 \mathrm{DF}$ \\
\hline Antidepressantsat the end & $10(29.4 \%)$ & $16(53.5 \%)$ & $\mathrm{X} 2=2.8, \mathrm{P}=0.0911 \mathrm{DF}$ \\
\hline Depressive Episode MDD & $4(11.8 \%)$ & $2(6.7 \%)$ & $\mathrm{X} 2=0.1, \mathrm{P}=0.7881 \mathrm{DF}$ \\
\hline Depressive Episode BP & $3(8.8 \%)$ & $2(6.7 \%)$ & $\mathrm{X} 2=0.1, \mathrm{P}=0.8841 \mathrm{DF}$ \\
\hline $\begin{array}{c}\text { Adjustment Disorder with De- } \\
\text { pressed Mood }\end{array}$ & $20(58.8 \%)$ & $16(53.3 \%)$ & $\mathrm{X} 2=0.1, \mathrm{P}=0.9371 \mathrm{DF}$ \\
\hline Dysthymia & $7(20.6 \%)$ & $10(33.3 \%)$ & $\mathrm{X} 2=2.0, \mathrm{P}=0.1551 \mathrm{DF}$ \\
\hline
\end{tabular}

drug as one unit, and totaling the units for each patient. For example: Fluoxetine $20 \mathrm{mg}=1$; Clomipramine $75 \mathrm{mg}=1$; Mirtazapine $30 \mathrm{mg}=1$. Thus, $10 \mathrm{mg}$ of Fluoxetine $(=0,5)$ plus $60 \mathrm{mg}$ of Mirtazapine $(=2)$ made a total of 2.5.

\section{Statistical Analysis}

The analysis of the data was carried out with the help of the statistical open source software R (Project for statistical Computing [http://www.r-project.org/]). Test $\chi^{2}$ was used for the comparison of data on a nominal scale. Analysis of Variance (ANOVA)was used for the comparison of data on a numerical scale. Multivariate Analysis of Variance (MANOVA) was used for the comparison of data on a numerical scale, evaluating the effect of the counseling within and between the groups over time.

\section{RESULTS}

\section{Characteristics of the Groups at the Beginning of the Trial (T0)}

In the experimental group, five patients (11.9\%) were suffering from a Major Depressive Episode with likeliness of Major Depression; four patients $(9.5 \%)$ from a Major Depressive Episode with likeliness of Bipolar Disorder (I, II or NOS); 25 (59.5\%) patients from an Adjustment Disorder with Depressed Mood; and eight (19.0\%) patients from Dysthymia.

The main concomitant diagnoses were: Personality Disorder of Cluster B: six cases (14.3\%); Panic Disorder: four cases (9.5\%); Social Phobia: three cases (7.1\%); General Anxiety Disorder: five cases (11.9\%); Obsessive Compulsive Disorder: one case (2.4\%); Bulimia: four cases $(9.5 \%)$; Eating Disorder NOS: three cases (7.1\%); Substances Abuse or Dependence: five cases $(11.9 \%)$. Of the 42 control patients, $28(66.7 \%)$ were females and $14(33.3 \%)$ were males.

The diagnoses in the control group were Major Depressed Episodes that would likely lead to Major Depression: three cases $(7.1 \%)$; Major Depressed Episodes that would likely lead to Bipolar Disorder (I, II or NOS):three cases (7.1\%); Adaptation Disorder with depressed mood, 21 cases (50\%); Dysthymia: 15 cases $(35.7 \%)$.

The main concomitant diagnoses were: Personality Disorder Cluster B: four cases (9.5\%); Panic Disorder: five cases (11.9\%); Social Phobia: two cases (7.1\%); General Anxiety Disorder: four cases (9.5\%); Obsessive Compulsive
Disorder: two cases (4.8\%); Bulimia: two cases (4.8\%); Eating Disorder NOS: two cases (4.8\%); Substance Abuse or Dependence: four cases $(9.5 \%)$.

Perhaps we should tabulate these above information

\section{Characteristics of Sample Completing the Trial}

The characteristics of the sample completing the trial are shown in Table 1. Of the 42 patients in the experimental group, 34 concluded the trial. Of the eight who missed the follow-up (19.0\%), four gave no reason $(9.5 \%)$, three indicated to the GP that they had problems of "understanding" or "communication" with the counselor (7.1\%). One subject was unable to continue the therapy due to work-related reason $(2.4 \%)$.

Of the 42 patients in the control group, 12 patients $(26.7 \%)$ did not attend the scheduled evaluation visit

There was no significant difference in follow-up absenteeism between the experimental group and the control group $(\chi 2=1,23,1 \mathrm{DF}, \mathrm{P}=0.27)$.

The final evaluations were carried out for 34 cases in the experimental group and 30 cases in control group.

\section{Depressive Symptoms, General Clinical Condition and Quality of the Life}

Table 2 shows scores for BDI (depressive symptoms), CGI (general clinical condition) and WHQOL-BREF (quality of the life) of patients in the experimental and control groups at the 3 assessment points. In addition, the results of comparisons between experimental and control group at T0, $\mathrm{T} 1$ and T2 as well as comparisons within each group across the three assessment points are also shown.

As shown, BDI had improved in the both groups at T1, and the improvement was even greater at T2. However, at T2 there was a significant difference between the two groups, with a lower score in the experimental group. Moreover, while the global clinical judgment (CGI) had not improved in the control group, it did so in the experimental group at T2 compared to T1. At T2, the CGI scores were lower in the experimental group than in the control group. Finally, the Quality of the life (WHQOL-BREF) had also improved in the experimental group compared to the control group from T0 to T2. These results indicate a positive effect of the counseling on patient recovery that can be recorded within 3 months of starting the treatment regimen. 
Table 2. Multivariate Analysis of Variance (MANOVA) of the Performance of the Cases and Control Groups

\begin{tabular}{|c|c|c|c|c|c|}
\hline Evaluation & to & t1 & t2 & & \\
\hline BDI Experimental Cases* & $18.7+/-9.1$ & $10.6+/-5.2$ & $6.3+/-4.7$ & $\begin{array}{c}\text { F interaction } 3.019 \\
\text { DF: } 2,226\end{array}$ & $\begin{array}{c}\mathrm{p} \text {-value } \\
0.0497699\end{array}$ \\
\hline \multirow[t]{2}{*}{ BDI Controls** } & $17.1+/-6.4$ & $12.3+/-8.2$ & $10.2+/-8.3$ & $\begin{array}{c}\text { F groups } 1.962 \\
\text { DF: } 1,226\end{array}$ & $\begin{array}{c}\mathrm{p} \text {-value } \\
0.1626876 \\
\end{array}$ \\
\hline & & & & $\begin{array}{c}\text { F time } \quad 35.559 \\
\text { DF: } 2,226\end{array}$ & $\begin{array}{c}\mathrm{p} \text {-value } \\
0.0000000\end{array}$ \\
\hline CGI Experimental Cases & $3.3+/-0.9$ & $3.0+/-1.1$ & $2.7+/-0.8$ & $\begin{array}{c}\text { F interaction } 1.864 \\
\text { DF: } 2,246\end{array}$ & $\begin{array}{c}\mathrm{p} \text {-value } \\
0.1571592\end{array}$ \\
\hline \multirow[t]{2}{*}{ CGI Controls } & $3.2+/-0.7$ & $3.1+/-0.8$ & $3.1+/-0.7$ & $\begin{array}{c}\text { F groups } 1.570 \\
\text { DF: } 1,246\end{array}$ & $\begin{array}{c}\mathrm{p} \text {-value } \\
0.2113954\end{array}$ \\
\hline & & & & $\begin{array}{c}\text { F time } 3.631 \\
\text { DF: } 2,246 \\
\end{array}$ & $\begin{array}{c}\mathrm{p} \text {-value } \\
0.02792359 \\
\end{array}$ \\
\hline WHQOL Cases & $68.5+/-14.4$ & $62.7+/-10.8$ & $58.6+/-12.3$ & $\begin{array}{c}\text { F interaction } 3.001 \\
\text { DF: } 2,246\end{array}$ & $\begin{array}{c}\mathrm{p} \text {-value } \\
0.04495382 \\
\end{array}$ \\
\hline \multirow[t]{2}{*}{ WHQOL Controls } & $64.3+/-11.3$ & $63+/-12.3$ & $62.8+/-9.8$ & $\begin{array}{c}\text { F groups } 0.004 \\
\text { DF: } 1,246\end{array}$ & $\begin{array}{c}\mathrm{p} \text {-value } \\
0.946898\end{array}$ \\
\hline & & & & $\begin{array}{c}\text { F time } 4.911 \\
\text { DF: } 2,246\end{array}$ & $\begin{array}{c}\mathrm{p} \text {-value } \\
0.0081015\end{array}$ \\
\hline
\end{tabular}

$*$ Cases $\mathrm{N}=34, * *$ Controls $\mathrm{N}=30$

To statistically confirm the difference between the experimental and control groups, we used Multivariate Analysis of Variance (MANOVA) and evaluated the effect of the counseling within and between the groups over time. The results of this analysis are shown in Table 2. As shown, a significant difference between time and treatments was found in terms of BDI and WHQOL but not for CGI.

\section{Use of Antidepressant Drugs}

Out of 42 patients in the experimental group, 28 used antidepressants (15 SSRI, 10 SNRI, 3 other) at the onset of the trial, with an average dosage of $1.2 \pm 0.3$.Of these, 8 used antidepressants at sub-threshold dosagesand 6 used more than one antidepressant. 14 patients also took benzodiazepine and 4 patients took benzodiazepine alone. Among those who completed the study (34), 10 used antidepressants, of which 5 were under-dosed. Of the 42 controls, 34 used antidepressants (18 SSRI, 8 SNRI, 8 others) upon entering the trial, with an average dosage of $1.1 \pm 0.4$. Of these, 8 used antidepressants at sub-threshold dosagesand 10 used more than one antidepressant. 10 also took benzodiazepine and 6 were prescribed benzodiazepine alone. The difference in the proportion of people taking antidepressants at the end of the trial is not statistically significant between experimental and control groups $\left(\chi^{2}=2.8,1 \mathrm{DF}, \mathrm{P}=0.91\right)$.

\section{DISCUSSION}

The literature reviewed shows consistent evidence that counseling improves quality of life in cancer and other chronic diseases $[27,28]$. This is the first study producing evidence that counseling as adjunctive treatment improves Quality of Life in patients attending primary care for depression.

Despite an expansion of GP based counseling at primary care settings, there is limited evidence for the effectiveness of this approach [29-32]. In a retrospective analysis of an earlier study [29] non-directive counseling was found to be more effective in the subgroup of patients who scored above a threshold of 14 on BDI. Then a large controlled trial of Ward and Coll. [33] confirmed that patients who scored $\geq 14$ on BDI recovered more quickly if followed with counseling for 4 months rather than under the care of general practitioner. But, after 12 months of follow-up, the patients in all study groups (2 of psychotherapies, one of usual GP care) had improved to the same extent. The lack of a significant difference between the treatment groups appears to have resulted from an improvement of patients in the GP care group from t4-month to 12-month follow-ups [33].

Our study shows that counseling, in addition to TAU in a primary care setting is more effective in reducing symptoms of depression after six months of treatment than TAU alone. Moroever, the added counseling regimen produced significant improvements in the quality of life measured by WHOQOL-BREF. In fact the continued difference in the depressive symptoms, between experimental group and control group, for a much longer duration compared to the one observed by Ward and Coll [33] is likely due to the fact that the counseling was administered for a much longer time (six month) in our study.

A recent trial in India found that a collaborative care intervention led by trained lay counselor can improve recovery from Common Mental Disorders among patients compared to the patients who received the usual primary care without any additional intervention [34]. In this study the "collaborative stepped-care intervention" offered case management and psychosocial interventions, provided by a trained lay health counselor, supplemented by antidepressant drugs by the primary care physician and supervision by a mental health specialist [34].

However, in this above trial as was in our present study, the target of the counseling treatment was not a particular diagnosis (as for example "Major Depressive Disorder") but a broad range of disorders [Common Mental Disorders in Patel and Coll [34] and "Depression" including a broad range of mental disorders in our current study]. 
One of the determinants of the efficacy of the counseling in these studies may be related with the use of the treatment, according to its use in the real practice, against a large even sub- threshold spectrum of affective diseases than to use counseling for single targeted diagnosis as in clinical randomized trial (RCT).

Another issue common to the Indian trail and our present study is that the assignment of patients between experimental treatments versus controls will be the casein a rigid like RCT method (e.g., "pharmacotherapy with counseling" or "counseling alone"). The assignment was done in a flexible manner (as one would find in a real primary care setting) allowing the GP to decide which patient should take antidepressants, which patient should be treated with counseling, etc.

The fact that counseling may be useful in a non-restricted target of patients is of particular utility in primary care settings. In such settings, the clinical finding of a GP is often a diagnosis of "depression", but it may be one of the signs of an evolving psychopathology, even though often this may not be obvious [35]. Patients who have functional somatic symptoms [36], such as anxiety, personality disorder, eating and substance abuse disorders associate themselves with depressed episodes, however, it is difficult to establish which occurred first, and therefore the connection between depression and these mental disorders [37]. For these reasons, it may be difficult to adopt the RCT model in a primary care, General Practice setting and more flexible models such as those adopted in our study as well as in the Indian study [34], may be better suited and complementary to the RCT.

According to a recent study, patient preference and expectation about treatment options appears to play a role in the outcome of the treatmentregimen in primary care settings [38]. A better outcome was observed with in patients who preferred say psychotherapies and were given psychotherapies as opposed to those who were given psychotherapies even though patients did not show preference to such a treatment. Similar results were also observed with drugs as well. Thus, it is important to consider this as a significant factor in a clinical trial involving psychological treatment for depression. The treatment choice of the GP depending up on the preference of the patient is possible ina flexible model such as the strategy used in our study. This model takes into consideration patient-doctor relationship as opposed to the more structured RCT, which does not consider patient choice.

A large amount of studies show that antidepressants are an effective treatment for depression in general practice [39, 40]. Antidepressant drugs present a "wide spectrum", that are able to improve a majority of anxiety symptoms [40]. Nevertheless, given the symptomatic complexity involved in cases of substance dependences, bipolar disorders or personality disorders, a counseling intervention used in a flexible manner clearly represents a better option than drugs alone. This approach also offers a low cost supplementary tool. Moreover antidepressants must be used with caution in specific certain types of patients such as in adolescents and those with bipolar disorder [41].

The proposed model (with counseling carried out in the general practice or primary care clinics) has obvious differences with other models proposed, particularly with the "Bo- logna Project" [7]. In Bologna model, psychiatric interventions integrating general medicine creates a specialized service outside the general medicine setting. The GP, in this case favors consultancy beyond his own practice. In our opinion, the Bologna model would be difficult to apply in isolated rural areas such as those represented in this study, where the GP clinic remain central to the treatment and the GP is a facilitator for counseling [42, 43].

To be sure, our study has limitations. For instance, only the GP were randomized and the patients were not. Furthermore, the sample size was small and the control group was not subject to any placebo effect of the counseling, making it difficult to measure, if any, of the improvement is due to some non-specific therapeutic effect. Perhaps our flexible model should be evaluated in a larger sample size along with complementary more focused RCT.

\section{CONCLUSION}

While this small-scale study needs to be replicated on a larger scale, the model presented appears to offer enhanced benefits of counseling intervention and particularly useful in isolated areas.

\section{CONFLICT OF INTEREST}

The authors confirm that this article content has no conflicts of interest.

\section{ACKNOWLEDGEMENT}

Declared none.

\section{REFERENCES}

[1] Ustun TB, Ayuso-Mateos JL, Chatterji S, Mathers C, Murray CJ. Global burden of depressive disorders in the year 2000. Br J Psychiatry 2004;184: 386-92.

[2] Simon GE. Social and economic burden of mood disorders. Biol Psychiatry 2003; 54(3): 208-15.

[3] Lerner D, Adler DA, Chang H, et al. Unemployment, job retention, and productivity loss amongemployeeswith depression. Psychiatr Serv 2004; 55: 1371-8.

[4] Goldberg D, Lecrubier Y. In: Mentallllness in General Health Care: an International Study. Form and frequency of mentaldisordersacross centers. Ustun T, Sartorius N, Eds. Chichester: John Wiley \& Sons 1995.

[5] Menchetti M, Bortolotti B, Rucci P, Scocco P, Bombi A, Berardi D; DEPICS Study Group. Depression in primary care: interpersonal counseling vs selectiveserotoninreuptakeinhibitors. The DEPICS Study. A multicenterrandomizedcontrolled trial. Rationale and design. BMC Psychiatry 2010; 10: 97.

[6] King M, Nazareth I, Levy G, et al. Prevalence of common mentaldisorders in general practiceattendeesacross Europe. Br J Psychiatry 2008; 192: 362-7.

[7] Berardi D, Leggieri G, Menchetti M, Ferrari G. Collaboration Between Mental Health Services and Primary Care: the Bologna Project. Prim Care Companion J Clin Psychiatry1999; 1(6): 180-3.

[8] Carta MG, Balestrieri M, Bocchetta A, et al. The use of antidepressant drugs in Italy. In: Syllabus, Psychiatric Services APA Congress. New York: APA 2009.

[9] Tylee A, Jenkins R. Counselling in primary care. Br J Gen Pract1998; 48(435): 1700-1.

[10] Kates N, Craven M, Crustolo AM, et al. Integrating mental health services within primary care. A Canadian program. Gen Hosp Psychiatry $1997 ; 19(5): 324-32$.

[11] Regione Sardegna, Sardegna Statistiche 2011, Available at: http://www.sard-egnastatistiche.it/index.php?xsl=362\&s=12\&v=9$\& \mathrm{c}=3185$ 
[12] Bonfiglioli S. Las transformacionesurbanas: impactosobreeltiempoyelhorario, 2011. Available at http://jornadausosdeltemps.net/do-cs/pon_bonfiglioli.pdf

[13] Amaddeo $\overline{\mathrm{F}}$, Zambello F, Tansella M, Thornicroft G. Accessibility and pathways to psychiatric care in a communitybasedmentalhealthsystem. Soc Psychiatry Psychiatr Epidemiol 2001; 36(10): 500-7.

[14] Fava GA, Rafanelli C, Grandi S, Conti S, Belluardo P. Prevention of recurrentdepression with cognitive behavioraltherapy: preliminaryfindings. Arch Gen Psychiatry 1998; 55(9): 816-20.

[15] Kingston T, Dooley B, Bates A, Lawlor E, Malone K. Mindfulness-based cognitive therapy for residual depressive symptoms. Psychol Psychother 2008; 80:193-203.

[16] Mantovani G, Astara G, Lampis B, et al. Evaluation by multidimensional instruments of health-related quality of life of elderly cancer patients undergoing three different "psychosocial" treatment approaches. A randomized clinical trial. Support Care Cancer 1996; 4(2): 129-40.

[17] Mantovani G, Astara G, Lampis B, et al. Impact of psychosocial interventions on quality of life of elderly cancer patients. PsychoOncology 1996; 5: 127-35.

[18] Carta MG, Hardoy MC, Pilu A, et al. Improving physical quality of life with group physical activity in the adjunctive treatment of major depressive disorder Clin Pract Epidemol Ment Health 2008; 4(1): 1.

[19] Carpiniello B, Piras A, Pariante CM, Carta MG, Rudas N. Psychiatric morbidity and family burden among parents of disabled children. Psychiatr Serv 1995; 46: 940-2.

[20] Morosini PL, Piacentini D, Leveni D, McDonald G, Michielin P. La depressione. Che cosa è e come superarla. Manuale di psicoterapia cognitivo-comportamentale per chi soffre di depressione, per chi è a rischio di soffrirne e per i suoi familiari. Avverbi Ed. Roma: 2004.

[21] Andrew G. What is depression. Available at: http://www.crufad.org/ind-ex.php/depression, 2011.

[22] American Psychiatric Association. Diagnostic Statistical Manual (DSM) IV-TR. Washington DC: APA 1994.

[23] Beck AT, Ward CH, Mendelson M, Mock J, Erbaugh J. An inventory for measuring depression. Arch Gen Psychiatry 196; 4: 56171.

[24] World Health Organization. Development of the World Health Organization WHOQOL-Bref Quality of Life Assessment. Psychol Med 1998; 28: 551-8.

[25] De Girolamo G, Rucci P, Scocco P, et al. Quality of life assessment: validation of the Italian version of the WHOQOL-Bref. Epidemiol Psichiatr Soc 2000; 9(1): 45-55.

[26] Guy W. Clinical Global Impression. In ECDEU Assessment Manual for Psychopharmacology, revised. Rockville MD: US Department of Health Education and Welfare 1976: pp. 217-22.

[27] Oranta O, Luutonen S, Salokangas RK, Vahlberg T, Leino-Kilpi H. The effects of interpersonal counselling on health-related quality of life after myocardial infarction. J Clin Nurs 2011; 20(23-24): 337382.

[28] Celasin H, Karakoyun R, Yılmaz S, Elhan AH, Erkek B, Kuzu MA. Quality of life measures in Islamic rectal carcinoma patients receiving counselling. Colorectal Dis 2011; 13(7): e170-5.
[29] Friedli K, King M, Lloyd M, Horder J. Randomised controlled assessment of non-directive psychotherapy versus routine generalpractitioner care. Lancet 1997; 350: 1662-5.

[30] Harvey I, Nelson S, Lyons R, Unwin C, Monaghan S, Peters T. A randomized controlled trial and economic evaluation of counselling in primary care. Br J Gen Pract 1998; 48: 1043-8.

[31] Scott A, Freeman C. Edinburgh primary care depression study: treatment outcome, patient satisfaction, and cost after 16 weeks. BMJ 1992; 304: 883-7.

[32] Roth A, Fonagy P. What works for whom? A criticalreview of psychotherapy research. London: Guildford 1996.

[33] Ward E, King M, Lloyd M, et al. Addington-Hall J Randomised controlled trial of non-directivecounselling, cognitive-behaviourtherapy, and usual general practitioner care for patients with depression. I: clinical effectiveness. BMJ 2000; 321(7273): 1383-8.

[34] Patel V, Weiss HA, Chowdhary N, et al. Effectiveness of an intervention led by lay health counsellors for depressive and anxiety disorders in primary care in Goa, India (MANAS): a cluster randomized controlled trial. Lancet 2010; 376(9758): 2086-95.

[35] Gilchrist G, Hegarty K, Chondros P, Herrman H, Gunn J. The association between intimate partner violence, alcohol and depression in family practice. BMC Fam Pract 2010; 11: 72.

[36] Toft T, Rosendal M, Ørnbø 1 E, Olesen F, Frostholm L, Fink P. Training general practitioners in the treatment of functional somatic symptoms: effects on patient health in a cluster-randomised controlled trial (the FunctionalIIlness in Primary Care study). Psycho ther Psychosom 2010; 79(4): 227-37.

[37] Kartal M, Coskun O, Dilbaz N. Recognizing and managinganxietydisorders in primaryhealth care in Turkey. Fam Pract 2010; 11: 30 .

[38] Mergl R, Henkel V, Allgaier AK, et al. Are treatment preferencesrelevant in response to serotonergicantidepressants and cognitivebehavioraltherapy in depressedprimary care patients? Results from a randomizedcontrolled trial including a patients' choicearm. Psychother Psychosom 2011; 80(1): 39-47.

[39] Arroll B, Elley CR, Fishman T, et al. Antidepressants versus placebo for depression in primary care. Cochrane Database Syst Rev 2009; 3: CD007954.

[40] Carta MG, Balestrieri M, Murru A, Hardoy MC. Adjustment Disorder: epidemiology, diagnosis and treatment. Clin Pract Epidemiol Ment Health 2009; 5: 15.

[41] Carta MG, Angst J. Epidemiological and clinical aspects of bipolar disorders: controversies or a common need to redefine the aims and methodological aspects of surveys. Clin Pract Epidemol Ment Health $2005 ; 1(1): \quad 4$. http://www.ncbi.nlm.nih.gov/entrez/query.fcgi? $\mathrm{cmd}=$ Retrieve $\& \mathrm{db}=$ pubmed $\&$ dopt $=$ Abstract\&list_uids $=$ $15967053 \&$ query $h \mathrm{l}=1 "$

[42] Cabras PL, Hardoy MJ, Hardoy MC, Carta MG. Clinical Experience with gabapentin in patients with Bipolar or Schizoaffective Disorder. J Clin Psychiatry 1999; 60(4): 245-8.

[43] Carta MG, Kovess V, Hardoy MC, Brugha T, Fryers T, Lehtinen V, M. Xavier Psychosocial wellbeing and psychiatric care in the European Communities: analysis of macro indicators. Soc Psychiatr Psychiat Epidemiol 2004; 39(11): 883-92.

Received: May 01, 2012

Revised: May 14, 2012

Accepted: May 14, 2012

(C) Carta et al.; Licensee Bentham Open.

This is an open access article licensed under the terms of the Creative Commons Attribution Non-Commercial License (http://creativecommons.org/licenses/by-nc/3.0/) which permits unrestricted, non-commercial use, distribution and reproduction in any medium, provided the work is properly cited. 